CAS E

or

\title{
CONGENITAL ABSENCE
}

OF THE

\section{PERICARDIUM,}

WITH

OBSERVATIONS.

Br T. B. CURLING,

Asgistant SURGEON TO THE LONDON hOSPITAL, etc.

READ APRIL 23RD, 1839.

THE subject of this uncommon malformation was a gardener, aged forty-six, who was admitted into the London Hospital under the care of Dr. Gordon, January 28th, 1839. After exposure to wet he had been seized with symptoms of paralysis, which commenced in the lower extremities, and gradually extended upwards until, the muscles of respiration becoming affected, asphyxia ensued, and he died on the 18th of February. He had previously enjoyed a good state of health, but, before the age of puberty, had been subject to attacks of profuse epistaxis. No- 
thing remarkable was observed in the action of the heart, or in the pulse.

I will not occupy time by a minute detail of the morbid appearances found in the inspection of the body after death, since they are not connected with the curious malformation which it is my object to submit to the notice of the Society, though some of them are unusual, and by no means devoid of interest. It is sufficient to mention, that they consisted of ramollissement of the central part of the whole medulla spinalis, deep injection of the mucous membrane of the bladder, and prostatic and membranous parts of the urethra, suppuration of Cowper's gland, and deposits of lymph in the substance of the testicles, with adhesions of the tunica vaginalis. On opening the cavity of the chest, by raising the sternum with the costal cartilages, I was much astonished at finding the heart completely exposed, lying loose in the cavity of the left pleura, in immediate contact with the lung, without any appearance whatever of pericardium. The heart was rather large and flabby, and in its natural position in the chest. On the anterior part of the left ventricle there was a small white opaque patch, and there was another of larger size on the posterior surface of the right ventricle. Nearly the whole front of the right ventricle was coated with a layer of fat. The vessels connected with the heart exhibited nothing remarkable, their relation being perfectly natural. On introducing the little finger into the aorta, its valves appeared to be healthy. The heart was a little overlapped by the 
anterior edge of the inferior lobe of the left lung, to which it was connected by a slight adhesion about a quarter of an inch in length. The pleura covering that part of the left lung in contact with the heart, was opaque, white, and thickened. The pleura was easily traced from the left lung, along the large pulmonary vessels, to the heart, which it invested so as to form a reflected pericardium, thence passing over the pulmonary vessels on the right side, and the commencement of the aqrta, it went forwards to join the pleura costalis, being at first in close relation to the right pleura, to which it was connected by loose cellular tissue, but afterwards separating to leave space for the anterior mediastinum. On the right side of the heart, just above the junction of the inferior vena cava, and close to the diaphragm, there was a pouch in the serous membrane, with a defined margin inferiorly, into which the appendix of the auricle projected. The left phrenic nerve crossed the trachea opposite the first bone of the sternum, and, passing to the front, and rather to the right side of the heart, proceeded to the diaphragm along the anterior mediastinum. The right phrenic nerve passed between the two layers of the separate pleuræ, about two inches behind the left. The lungs were healthy, with the exception of a little emphysema at the margins of the lower lobes. There was an old adhesion half an inch wide, connecting the outer part of the upper lobe of the left lung to the pleura costalis.

A deficiency of the pericardium is admitted to be 
one of the most rare congenital deviations from normal structure to which the human body is liable, and there are very few well-authenticated cases of it on record. Haller* and Morgagni† have even denied that such a malformation ever existed, and they believed that the cases of absence of the membrane related by previous authors were merely instances of an intimate adhesion of the heart and pericardium. The incredulity of Haller on this point was strengthened by the discovery, on dissection, that certain animals, as the hedgehog and mole, which are represented by some of the old writers on comparative anatomy to be without a pericardium, are really not deficient in this membrane; and it is an interesting circumstance in connection with this malformation that, in all the inferior animals in which a perfect heart is found, this organ is always enclosed in a distinct sac or pericardium. The only genuine case of an absence of the pericardium met with in this country, which is on record, is described by $\mathrm{Dr}$. Baillie. $\ddagger$ It occurred to him, upon opening the cavity of the chest in a man about forty years of age, in order to explain at lecture the situation of the thoracic viscera, when he was exceedingly surprised to see the naked heart lying on the left side of the chest. The anatomical particulars of Dr. Baillie's case correspond very nearly with those in the exam-

* Elementa Physiologiæ, vol. i., lib. iv., sect. 1, p. 289.

+ Epist. xxiii., Nos. 17 and 18.

$\ddagger$ Trans. of a Society for the Improvement of Medical and Chirurgical Knowledge, vol. i., p. 91.

VOL. XXII. 
ple furnished in this communication, the imperfection being equally complete. Breschet has also recorded another undoubted case of this malformation.* A young man twenty-eight years of age, of habitual good health, and free from any disorder of the respiratory and circulating functions, was admitted into the Hotel Dieu of Paris, December 5th, 1825, on account of acute dysentery, of which he died in three days. On a careful inspection of the body, besides the morbid appearances in the mucous membrane of the intestines, it was found that there was no pericardium, the heart being contained in the left cavity of the chest. The heart was retained in its situation by two bridles two inches in length, which proceeded from the left side of its apex to the diaphragm, to which they were attached. In Dr. Baillie's case there was no trace whatever of the pericardium ; but in the example described by Breschet there were distinct vestiges of the existence of this membrane, consisting of a shallow depression or capsule on the left side of the mediastinum, close to the diaphragm, and a cylindrical fibrous filament, crossing the base of the heart without adhering to it. The capsule alluded to by Breschet was evidently very similar to the pouch which I met with close to the right auricle in the present case, but this was the only rudiment of a pericardium that I could detect. In all these cases the heart was invested with a serous membrane, continuous with the left pleura, which formed a perfect reflected pericardium, and, alike in

* Répertoire Général d'Anatomie, t. i., p. 67. 
all three, the left phrenic nerve deviated from its usual course, passing nearer the mesial line of the body. This alteration in the course of the left phrenic nerve, and the absence of a close union between the heart and diaphragm, will always be sufficient to distinguish congenital deficiency of the pericardium from universal adhesion of that membrane to the heart.

The following cases, although the anatomical details are imperfectly given, must also be viewed as instances of this malformation.

Dr. Woolf* relates that a woman, aged fortytwo, died of typhus fever at a late period of pregnancy. Spontaneous delivery took place after death. On examination of the body the day after her decease, it was found a good deal distended with gas, which appeared to have caused extroversion of the uterus, and the birth of the child. There was a complete absence of the pericardium, the heart being free on the left side of the thorax, and in its usual position. The heart was very large, but not at all loaded with adipose tissue, although the rest of the body was extremely fat. It was of a yellowish-brown red colour, and easily broken down with the fingers. The auricles were of great size, thin, and of soft texture. No trace of the pericardium could be discovered about the great vessels. The outer membrane of the heart was present, but it was rather thinner, and more lax in texture than usual. The * Rust's Magazin für die gesammte Heilkunde, vol. xxiii., p. 333 . 
husband stated that the deceased had enjoyed good health; but when under the influence of mental emotion, or suffering from severe bodily exertion, she had complained of constriction and oppression at the chest, and violent palpitations of the heart.

A preparation exhibiting a deficiency of the pericardium, taken from a man twenty years of age, is described by Walter in his Museum Anatomicum. The heart was observed lying naked in the same cavity with the left lung, the pericardium being entirely wanting.*

M. Littre, on examining the body of a woman fifty-four years of age, found the heart without any pericardium, and included absolutely naked in the cavity of the chest. The heart was hard, dry, unequal, and rough, and bad little fat. $\dagger$

The case noticed by Realdus Columbus, of a young student at Rome who died in a state of syncope, and whose heart was devoid of a pericardium ; t that related by Tulpius, of a young man subject to violent palpitations of the heart, fainting fits, and an intermittent pulse, whose heart was found after death very large, and without a pericardium ; $\$$ and the case mentioned by Bartholinus; $\|$ cannot be received as genuine instances of this malformation.

The anomaly presented by a heart which had duly

* No. 668 .

$\uparrow$ Histoire de l'Acad. Roy. des Sciences, 1712, p. 37.

† De Re Anat. lib. xŕ., p. 265.

Obs. Med., lib. ii., chap. xxv., p. 134.

\| Hist. Anat., Cent. iv., No. 20. 
performed its 'work for forty years without a pericardium, induced Dr. Baillie to speculate on the uses of this membrane, which he was inclined to think are not very important. He remarks, that " the more striking use of a pericardium is to keep the heart in a steady situation, so as to enable it to carry on its functions uniformly."* He omits however to notice one material advantage gained by the heart being enclosed in a serous bag separate from that of the lung, which is, a greater exemption from the effects of inflammation. Thus there is no morbid lesion more often recognised after death than pleuritic adhesions, and there are few diseases of more common occurrence than inflammation of the pleura. Now had the heart been always contained in a common sac with the lung, its serous investment must necessarily have often shared in the inflammation so frequently affecting the pleura, and thus an organ, the motions of which should always be free and unrestrained, would be very liable to be interfered with by changes, which, though of little consequence. in regard to the lungs, almost invariably lead to serious disease of the heart. The slight adhesion between this organ and the lung, which existed in the case that I have related, could scarcely have caused any interruption to the actions of the heart. In Breschet's case there were two slender adhesions between the heart and diaphragm, which must have in some degree confined its movements. 
230 CASE OF ABSENCE OF THE PERICARDIUM.

Dr. Hodgkin* thinks it probable that the opaque white patches so frequently seen on the anterior surface of the heart are the effect of attrition. The appearance noticed in this case of a similar change in the pleura, investing only that part of the lung which is exposed to friction in the actions of the heart, tends to support this opinion.

March 1st, 1839.

* Lectures on the Morbid Anatomy of the Serous Membranes, p. 98. 